\title{
Associations between the Risk of Internet $\quad$ Original Associations between the Risk of Internet $\quad$ Article Addiction and Problem Behaviors among Korean Adolescents
}

\author{
Jisun Sung, Jungkwon Lee*, Hye-Mi Noh, Yong Soon Park ${ }^{1}$, Eun Ju Ahn
}

Department of Family Medicine, Samsung Medical Center, Sungkyunkwan University School of Medicine; ${ }^{1}$ Health Screening Center, Kangbuk Samsung Hospital, Sungkyunkwan University School of Medicine, Seoul, Korea

Background: The number of internet users is increasing rapidly and internet addiction among adolescents has become a serious public health problem in Korea. In the light of behavioral addiction, this study was aimed to identify the associations between the risk of internet addiction and other problem behaviors which can lead to addiction, such as cigarette smoking, alcohol drinking, drug abuse, and sexual intercourse among a nationally representative sample of Korean adolescents.

Methods: Data from the 2010 Korean Youth Risk Behavior Web-based Survey (respondents, 73,238) were analyzed. Risk of internet addiction was assessed by the 'Korean Internet Addiction Proneness Scale for Youth-Short Form: Self Report' which was developed by the Korean National Information Society Agency in 2008. Multiple logistic regression analysis was used to calculate the odds ratios of problem behaviors among adolescents at high risk for internet addiction and adolescents at low risk for internet addiction.

Results: The odds of smoking experience, drug abuse experience, and sexual intercourse experience were significantly higher among boys at high risk for internet addiction compared to boys at low risk for internet addiction. Among girls at high risk of internet addiction, the odds of smoking experience, drinking experience, and drug abuse experience were significantly higher compared with girls at low risk of internet addiction.

Conclusion: The risk of internet addiction was associated with cigarette smoking, alcohol drinking, drug abuse, and sexual intercourse experience among Korean adolescents.

Keywords: Internet; Adolescent; Addictive Behavior; Smoking; Alcohol Drinking; Sexual Behavior; Substance-related Disorders

Received: August 17, 2012, Accepted: December 27, 2012

${ }^{*}$ Corresponding Author: Jungkwon Lee

Tel: +82-2-3410-2441, Fax: +82-2-3410-0388

E-mail: jklee@skku.edu

Korean Journal of Family Medicine

Copyright (C) 2013 The Korean Academy of Family Medicine

(a) This is an open-access article distributed under the terms of the Creative Commons Attribution Non-Commercial License (http://creativecommons.org/licenses/by-nc/3.0) which permits unrestricted noncommercial use, distribution, and reproduction in any medium, provided the original work is properly cited.

\section{INTRODUCTION}

The number of internet users is increasing rapidly in Korea. According to a report on the 2011 survey conducted by the Korea Internet Security Agency, the proportion of internet users among the Korean population over the age of 7 years was $44.7 \%$ in 2000 and the proportion among the population over the age of 3 years was $78.0 \%$ in 2011 . In particular, $99.9 \%$ of teenagers used the internet in 2011. ${ }^{1 \text { ) }}$

Adolescents get academic information easily and enjoy 
social interactions and leisure with low cost through the internet. Excessive use of the internet, however, can have deleterious effects on psychosocial development and behavior of adolescents. ${ }^{2)}$ Depression, anxiety, sleep disorders, and psychiatric disorders including attention deficit hyperactivity disorder are known to be related to internet addiction. ${ }^{3-5)}$

The concept of 'internet addiction' as a discrete disease was first proposed in 1995 by Ivan Goldberg, a New York

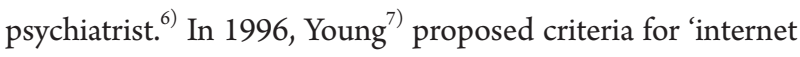
addiction' patterned after the Diagnostic and Statistical Manual of Mental Disorders (DSM)-IV criteria for pathological gambling. Young's study dividing computer users into two groups, dependents and non-dependents, using the criteria, triggered controversy. Young said that on-line users could become addicted to the internet in the same way that others became addicted to drugs or alcohol, resulting in academic, social, and occupational impairment. In controversies, other investigators suggested several alternative terms including 'compulsive internet use,' 'pathological internet use,' 'problematic internet use,' and 'internet dependency,' and they proposed many diagnostic criteria. ${ }^{8,9)}$ In the draft diagnostic criteria for DSM-V released in 2010, the American Psychiatric Association considered internet addiction part of the 'behavioral addictions' category, but work group members decided there was insufficient research data to do so. ${ }^{10)}$

Despite the lack of definite diagnostic criteria, there is no doubt that internet addiction has become a serious public health problem in Asia, including Korea. ${ }^{11-13)}$ Therefore, studies concerning various factors related to internet addiction are conducted actively to understand and solve internet addiction phenomenon. ${ }^{4,12)}$ In light of behavioral addiction, researchers have been making efforts to find an association between internet addiction and other problem behaviors which can lead to addiction, such as alcohol drinking and drug abuse. Ko et al. ${ }^{14)}$ found that internet addiction was associated with problematic alcohol use, and psychosocial proneness towards problem behaviors is associated with internet addiction as well as problematic alcohol use in Taiwanese adolescents. Yen et al. ${ }^{15)}$ also reported that internet addiction was associated with harmful alcohol use in Taiwanese college students. June et al. ${ }^{16)}$ evaluated the relationships among internet addiction, cigarette smoking, and alcohol drinking in 1,592 Korean high school students. She concluded that smoking and drinking were interrelated with each other, but internet addiction was not related either with smoking or drinking.

The aim of our study is to identify the association between a high risk of internet addiction and problem behaviors which can lead to addiction, including cigarette smoking, alcohol drinking, drug abuse, and sexual intercourse among Korean adolescents.

\section{METHODS}

\section{Data and Subjects}

Data from the 2010 Korean Youth Risk Behavior Webbased Survey (KYRBWS) were analyzed. ${ }^{17)}$ The KYRBWS is a government-approved statistical survey (Statistics Korea, approval No. 11758), which has been performed annually to monitor priority health risk behaviors among Korean adolescents by Korea Centers for Disease Control and Prevention since 2005. The 2010 KYRBWS was conducted from 1 September 2010 to 24 October 2010. A stratified multistage cluster-sampling design was used to obtain a nationally representative sample of middle and high school students for the survey. Students voluntarily completed the anonymous, self-administered web-based survey during a regular class period. The survey consisted of 128 questions assessing demographic characteristics and 14 areas of health-related behaviors, including cigarette smoking, alcohol drinking, obesity, physical activity, eating habit, injury prevention, sexual behaviors, mental health, oral health, allergic disorders, personal hygiene, internet addiction, drug abuse, and health equity. A total of 74,980 students from 400 middle schools and 400 high schools were engaged in the survey and the response rate was $97.7 \%$. The final study participants included 73,238 students (38,391 boys and 34,847 girls). Additional details on the sampling methodology and survey procedure are available elsewhere. ${ }^{18)}$ This study was reviewed and approved by the institutional review board at the Samsung Medical Center (SMC 2012-04-084).

\section{Measurements}

The 2010 KYRBWS borrowed the 'Korean Internet Addiction Proneness Scale for Youth-Short Form: Self Report (KS Scale)' to assess the risk of internet addiction. The KS Scale was developed by the Korean National Information Society 
Agency in 2008. ${ }^{19)}$ It was based on a cognitive-behavioral model of pathological internet use introduced by Davis ${ }^{20)}$ and a structural model of internet addiction suggested by Kim et al., ${ }^{19)}$ which showed causes, psychological mechanisms, and pathological symptoms of internet addiction. The KS Scale consists of 20 questions for each of the 6 categories assessing proneness to internet addiction, i.e., 'tolerance,' 'withdrawal,' 'addictive automatic thought,' 'disturbance of adaptive function,' 'deviate behaviors,' and 'virtual interpersonal relationship.' Each question was scored on a 4-point scale with higher points indicating higher risk of internet addiction. A total score obtained by combining the scores of the responses to the 20 questions was converted into a standardized score. The 'high risk group for internet addiction' was defined as the standardized total score being 70 points or higher and the standardized score for each of 3 categories, 'tolerance,' 'withdrawal,' and 'disturbance of adaptive function' being 70 points or higher. Cronbach's alpha score for the KS Scale for middle school students was 0.909 at the time of development. $^{21)}$

Lifetime smoking experience and lifetime drinking experience were defined as responding "yes" to the following questions: "Have you ever smoked a cigarette, even a single puff?" and "Have you ever drunk more than one glass of alcohol? A few sips of alcohol during religious rites is exceptional.” Early smoking experience and early drinking experience were defined as responding "before middle school" to the following questions: "How old were you when you first smoked a cigarette?" and "How old were you when you first drank alcohol?" Current smoking and current drinking were defined as responding "more than a day" to the following questions: "During the past 30 days, on how many days did you smoke at least one cigarette?” and "During the past 30 days, on how many days did you drink at least one glass of alcohol?” Drug abuse experience was assessed by the question, "Have you ever taken a drug like philopon, amphetamine, or opioid, or ever sniffed glue or butane gas for the purpose of feeling good, having hallucinations, or losing weight?” Lifetime sexual intercourse experience was defined as choosing "sexual intercourse with the opposite sex or with the same sex" to the following command: "Choose any sexual behavior that you have ever experienced.” Early sexual intercourse experience was defined as responding "before middle school" to the following questions: "How old were you when you first had sexual intercourse?"

Socio-demographic variables included gender, residing region, type of school, perceived academic performance, perceived family economic status, presence of parents, whether family lives together or not, and parents' level of education. We also used mental health status variables including depression, perceived stress, and perceived unhappiness.

\section{Statistical Analysis}

Descriptive analyses were carried out on all variables. Chi-square tests were used to compare socio-demographic characteristics, mental health status, and the proportions of problem behavior experiences including cigarette smoking, alcohol drinking, drug abuse, and sexual intercourse among high risk and low risk groups for internet addiction. Based on the previous study, problem behavior experiences were analyzed by gender, and there was a gender gap relative to participation in problem behaviors. Multiple logistic regression analysis was performed to find the association between internet addiction and adolescent problem behaviors. Age, socio-demographic and mental health variables which showed a significant difference in chi-square tests were adjusted for the analysis. The adjusted odds ratios (AOR) and corresponding 95\% confidence intervals (CI) were calculated. $\mathrm{P}<0.05$ was considered significant. All estimates were calculated based on sample weights, which were evaluated by taking into consideration the sampling rate, response rate, gender, school type, and grade proportions of the reference population. The analysis was adjusted for the complex sample design of the survey. All the data were analyzed using IBM SPSS ver. 20.0 (IBM Co., Armonk, NY, USA).

\section{RESULTS}

A total of 73,238 students were enrolled in the current study, of which $3.0 \%$ were classified as having a 'high risk for internet addiction.' The socio-demographic characteristics and mental health status of the subjects were provided in Table 1. The percentage of boys was higher in the high risk group for internet addiction than in the low risk group. There were no differences in residing regions or type of schools between the two groups. The proportions of students who thought their academic performance 
Table 1. Socio-demographic characteristics and mental health status of subjects

\begin{tabular}{|c|c|c|c|c|c|}
\hline \multirow[t]{2}{*}{ Characteristic } & \multicolumn{2}{|c|}{$\begin{array}{l}\text { Low risk group for internet addiction } \\
\qquad(\mathrm{n}=71,042)\end{array}$} & \multicolumn{2}{|c|}{$\begin{array}{l}\text { High risk group for internet addiction } \\
\qquad(\mathrm{n}=2,196)\end{array}$} & \multirow[t]{2}{*}{ P-value* } \\
\hline & No. (\%) & SE & No. $(\%)$ & SE & \\
\hline Boys & $36,879(52.3)$ & 1.6 & $1,512(69.3)$ & 1.8 & $<0.001$ \\
\hline \multicolumn{6}{|l|}{ Residing region } \\
\hline Rural & $8,738(5.3)$ & 0.3 & $318(6.5)$ & 0.6 & \\
\hline Small city & $25,272(40.5)$ & 1.0 & $794(40.8)$ & 1.8 & 0.15 \\
\hline Large city & $37,032(54.1)$ & 0.9 & $1,084(52.7)$ & 1.8 & \\
\hline \multicolumn{6}{|l|}{ Type of school } \\
\hline Middle school & $36,434(50.1)$ & 0.9 & $1,136(50.4)$ & 1.8 & \\
\hline General high school & $26,079(38.1)$ & 0.8 & 766 (36.5) & 1.7 & 0.36 \\
\hline Vocational high school & $8,529(11.8)$ & 0.5 & $294(13.1)$ & 1.1 & \\
\hline \multicolumn{6}{|l|}{ Perceived academic performance } \\
\hline Very high & $8,143(11.5)$ & 0.2 & $216(9.7)$ & 0.8 & \\
\hline High-middle-low & $54,503(76.9)$ & 0.2 & $1,444(65.7)$ & 1.2 & $<0.001$ \\
\hline Very low & $8,396(11.6)$ & 0.2 & $536(24.6)$ & 1.0 & \\
\hline \multicolumn{6}{|l|}{ Perceived family economic status } \\
\hline Very high & $4,608(6.9)$ & 0.2 & $170(7.9)$ & 0.7 & \\
\hline High-middle-low & $62,233(87.5)$ & 0.2 & $1,704(77.7)$ & 1.1 & $<0.001$ \\
\hline Very low & $4,201(5.6)$ & 0.1 & $322(14.4)$ & 0.9 & \\
\hline \multicolumn{6}{|l|}{ Presence of parents } \\
\hline Both & $67,190(95.2)$ & 0.1 & $1,998(91.2)$ & 0.7 & \\
\hline Fatherless or motherless & $2,940(3.7)$ & 0.1 & $137(5.8)$ & 0.6 & $<0.001$ \\
\hline Parentless & $912(1.1)$ & 0.1 & $61(3.0)$ & 0.5 & \\
\hline Family lives together & $67,327(95.6)$ & 0.3 & $2,015(92.0)$ & 0.8 & $<0.001$ \\
\hline \multicolumn{6}{|l|}{ Father's education level } \\
\hline Complete middle school or less & $4,211(6.1)$ & 0.2 & $192(10.1)$ & 0.9 & \\
\hline Complete high school & $25,266(41.0)$ & 0.7 & $734(41.4)$ & 1.4 & $<0.001$ \\
\hline Complete college or more & $28,935(52.9)$ & 0.7 & $766(48.7)$ & 1.5 & \\
\hline \multicolumn{6}{|l|}{ Mother's education level } \\
\hline Complete middle school or less & $4,144(6.2)$ & 0.2 & $168(9.3)$ & 0.9 & \\
\hline Complete high school & $32,943(54.8)$ & 0.7 & 944 (55.5) & 1.7 & $<0.001$ \\
\hline Complete college or more & $21,277(39.0)$ & 0.8 & $570(35.2)$ & 1.5 & \\
\hline Depression (recent 12 mo) & $26,116(36.8)$ & 0.3 & $1,257(57.1)$ & 1.3 & $<0.001$ \\
\hline Perceived stress & $30,614(43.1)$ & 0.3 & $1,480(66.7)$ & 1.2 & $<0.001$ \\
\hline Perceived unhappiness & $9,194(12.9)$ & 0.2 & $718(32.4)$ & 1.2 & $<0.001$ \\
\hline
\end{tabular}

*P-value from chi-square test comparing a difference between the 2 study groups. 
would be in the lowest quintile and who thought their family economic status would be in the lowest quintile were higher in the high risk group for internet addiction. The percentages of parentless students and students who didn't live with family were also higher in the high risk group. The proportion of students whose parents completed college was lower in the high risk group than in the low risk group. Regarding mental health status, there were marked differences between the high risk group for internet addiction and the low risk group. The high risk group (57.1\%) students reported that they experienced depression while the low risk group (36.8\%) reported experiencing depression. The proportions of students who felt stressed and unhappy were $66.7 \%$ and $32.4 \%$ in the high risk group, and $43.1 \%$ and $12.9 \%$ in the low risk group, respectively.

Significantly higher proportions were shown in all of the problem behavior variables which included lifetime smoking experience, early smoking experience, current smoking, lifetime drinking experience, early drinking experience, current drinking, lifetime drug abuse experience, lifetime sexual intercourse experience, and early sexual intercourse experience among the

Table 2. Problem behaviors according to the risk of internet addiction among boys

\begin{tabular}{|c|c|c|c|c|c|}
\hline \multirow[t]{2}{*}{ Problem behaviors } & \multicolumn{2}{|c|}{$\begin{array}{l}\text { Low risk group for internet addiction } \\
\qquad(\mathrm{n}=36,879)\end{array}$} & \multicolumn{2}{|c|}{$\begin{array}{l}\text { High risk group for internet addiction } \\
\qquad(\mathrm{n}=1,512)\end{array}$} & \multirow[t]{2}{*}{ P-value* } \\
\hline & No. $(\%)$ & SE & No. $(\%)$ & SE & \\
\hline Lifetime smoking experience & $12,278(32.5)$ & 0.5 & $645(41.9)$ & 1.5 & $<0.001$ \\
\hline Early smoking experience & $3,776(9.7)$ & 0.3 & $252(15.5)$ & 1.1 & $<0.001$ \\
\hline Current smoking & $6,137(16.3)$ & 0.4 & $345(22.9)$ & 1.4 & $<0.001$ \\
\hline Lifetime drinking experience & 20,977 (56.9) & 0.5 & $925(60.6)$ & 1.7 & 0.04 \\
\hline Early drinking experience & $6,595(17.6)$ & 0.3 & $358(23.1)$ & 1.5 & $<0.001$ \\
\hline Current drinking & $8,631(23.3)$ & 0.4 & $409(28.1)$ & 1.6 & 0.01 \\
\hline Lifetime drug abuse experience & $259(0.8)$ & 0.1 & $58(4.1)$ & 0.7 & $<0.001$ \\
\hline Lifetime sexual intercourse experience & $2,543(6.9)$ & 0.2 & $179(13.2)$ & 1.2 & $<0.001$ \\
\hline Early sexual intercourse experience & $543(1.5)$ & 0.1 & $75(5.9)$ & 1.0 & $<0.001$ \\
\hline
\end{tabular}

*P-value from chi-square test comparing a difference between the 2 study groups.

Table 3. Problem behaviors according to the risk of internet addiction among girls

\begin{tabular}{|c|c|c|c|c|c|}
\hline \multirow[t]{2}{*}{ Problem behaviors } & \multicolumn{2}{|c|}{$\begin{array}{l}\text { Low risk group for internet addiction } \\
\qquad(\mathrm{n}=34,163)\end{array}$} & \multicolumn{2}{|c|}{$\begin{array}{l}\text { High risk group for internet addiction } \\
\qquad(\mathrm{n}=684)\end{array}$} & \multirow[t]{2}{*}{ P-value* } \\
\hline & No. (\%) & SE & No. $(\%)$ & SE & \\
\hline Lifetime smoking experience & 6,208 (17.9) & 0.4 & $254(39.0)$ & 2.3 & $<0.001$ \\
\hline Early smoking experience & $1,847(5.4)$ & 0.2 & $100(13.7)$ & 1.5 & $<0.001$ \\
\hline Current smoking & $2,253(6.9)$ & 0.3 & $102(16.5)$ & 1.9 & $<0.001$ \\
\hline Lifetime drinking experience & $18,017(52.0)$ & 0.6 & $439(63.7)$ & 2.3 & $<0.001$ \\
\hline Early drinking experience & $4,724(13.6)$ & 0.3 & $162(23.2)$ & 1.8 & $<0.001$ \\
\hline Current drinking & $6,323(18.1)$ & 0.4 & $192(28.9)$ & 2.0 & $<0.001$ \\
\hline Lifetime drug abuse experience & $137(0.4)$ & 0.1 & $27(3.7)$ & 0.9 & $<0.001$ \\
\hline Lifetime sexual intercourse experience & $1,053(3.2)$ & 0.1 & $40(5.2)$ & 1.3 & 0.04 \\
\hline Early sexual intercourse experience & $217(0.7)$ & 0.1 & $13(1.6)$ & 0.6 & 0.02 \\
\hline
\end{tabular}

${ }^{*} \mathrm{P}$-value from chi-square test comparing a difference between the 2 study groups. 
Table 4. Associations between the risk of internet addiction and adolescent problem behaviors by gender

\begin{tabular}{lcc}
\hline \multicolumn{1}{c}{ Problem behaviors } & \multicolumn{2}{c}{ Adjusted OR* (95\% CI) } \\
\cline { 2 - 3 } & Boys & $1.88(1.48-2.39)$ \\
\hline Lifetime smoking experience & $1.18(1.01-1.38)$ & $1.84(1.33-2.55)$ \\
Early smoking experience & $1.30(1.04-1.62)$ & $1.45(1.03-2.04)$ \\
Current smoking & $1.11(0.90-1.36)$ & $1.33(1.02-1.73)$ \\
Lifetime drinking experience & $0.96(0.79-1.16)$ & $1.31(1.03-1.68)$ \\
Early drinking experience & $1.16(0.93-1.45)$ & $1.43(1.11-1.84)$ \\
Current drinking & $0.98(0.80-1.21)$ & $4.21(1.86-9.51)$ \\
Lifetime drug abuse experience & $4.30(2.49-7.42)$ & $0.84(0.45-1.54)$ \\
Lifetime sexual intercourse experience & $1.36(1.03-1.80)$ & $1.29(0.50-3.35)$ \\
Early sexual intercourse experience & $2.48(1.35-4.53)$ & \\
\hline
\end{tabular}

OR: odds ratio, CI: confidence interval.

*Analyzed by multiple logistic regression model, adjusted for age, perceived academic performance, perceived family economic status, presence of parents, whether family lives together or not, father's education level, mother's education level, depression, perceived stress, perceived unhappiness.

high risk group for internet addiction regardless of gender (Tables 2,3).

Table 4 showed the association between internet addiction and adolescent problem behaviors. The odds of lifetime smoking experience and early smoking experience were significantly higher among boys who were at high risk of internet addiction than for boys who were at low risk of internet addiction (adjusted odds ratio $[\mathrm{AOR}], 1.18$; 95\% confidence interval [CI], 1.01 to 1.38; AOR, 1.3; 95\% CI, 1.04 to 1.62). Girls who were at high risk of internet addiction had significantly higher odds of lifetime smoking experience, early smoking experience, and current smoking than girls at low risk of internet addiction (AOR, 1.88; 95\% CI, 1.48 to 2.39; AOR, 1.84; 95\% CI, 1.33 to 2.55; AOR, $1.45 ; 95 \% \mathrm{CI}, 1.03$ to 2.04$)$. The associations between the risk of internet addiction and lifetime drinking experience, early drinking experience and current drinking among boys were non-significant. However, among girls at high risk of internet addiction, the odds of lifetime drinking experience, early drinking experience, and current drinking were significantly higher than for girls at low risk of internet addiction (AOR, 1.33; 95\% CI, 1.02 to 1.73; AOR, 1.31; 95\% CI, 1.03 to 1.68; AOR, 1.43; 95\% CI, 1.11 to 1.84 ). The odds of lifetime drug experience were significantly higher among boys and girls who were at high risk of internet addiction than for boys and girls who were at low risk of internet addiction (AOR, 4.3; 95\% CI, 2.49 to 7.42; AOR, 4.21; 95\% CI, 1.86 to 9.51 ). Boys who were at high risk of internet addiction had significantly higher odds of lifetime sexual intercourse experience and early sexual intercourse experience than boys who were at low risk of internet addiction (AOR, 1.36; 95\% CI, 1.03 to 1.80 ; AOR, 2.48; 95\% CI, 1.35 to 4.53). No significant association was observed between internet addiction and lifetime sexual intercourse experience and early sexual intercourse experience for girls.

\section{DISCUSSION}

Youths at high risk of internet addiction showed a high rate of cigarette smoking, alcohol drinking, drug abuse, and sexual intercourse experience in our study. These findings should not be interpreted as implying that internet addiction causes other problem behaviors among adolescents; however, it is likely that the same causal factors responsible for internet addiction increase the risk of internet addiction in adolescents engaging in other problem behaviors. It is consistent with Problem-Behavior Theory-psychosocial proneness of Jessor, ${ }^{22)}$ which provides an explanation why adolescent problem behaviors and health risk behaviors cluster together. He suggested risk and protective 
factors for a "problem behavior syndrome" in 5 areas including biology/genetics, social environment, perceived environment, personality, and behavior, such as family history of alcoholism, poverty, conflicts with parents and friends, low self-esteem, and poor school work as risk factors, and high intelligence, quality school, models for conventional behavior, value on achievement and health, and church attendance as protective factors. ${ }^{23,24)}$

The risk of internet addiction still had high associations with cigarette smoking, alcohol drinking, drug abuse, and sexual intercourse experiences even after adjusting for perceived academic performance, economic status, and family environment such as parents' level of education, stress, and depression. This shows that the association between internet addiction and smoking, drinking, drug abuse, and sexual intercourse experiences cannot be explained simply by environmental factors, social factors, and mental health status.

Ko et al. ${ }^{25)}$ reported that Taiwanese adolescents with internet addiction were more likely to have substance use experience including tobacco, alcohol, or illicit drug use. He found that students addicted to the internet and students with substance use experience shared common personality characteristics more vulnerable to addiction. Similar findings among Greek adolescents were reported by Fisoun et al. ${ }^{26)}$ These studies suggested that adolescents at high risk of internet addiction may have personalities vulnerable to any addiction and the personalities increase the risk for substance use and sexual intercourse which can lead to addiction. Although the exact neurobiological mechanism explaining the addictive personality has not been found, serotonin and dopamine are known to play an important role. ${ }^{27)}$

Associations between internet addiction and problem behaviors differed between boys and girls in our study. Among girls, the risk of internet addiction was associated with all of the problem behavior variables except for sexual intercourse experience. However, in boys, sexual intercourse experience showed an association with the risk of internet addiction. This may be related to a report that boys with internet addiction visited websites with pornographic materials more frequently than girls with internet addiction. ${ }^{28)}$ In boys, the risk of internet addiction was not associated with alcohol drinking. This could be related to the part of Korean culture that is more generous to men regarding alcohol consumption than to women. But more research is necessary to identify the cause of gender differences.

The limitations of this study include the cross-sectional study design, which cannot prove a causal or temporal relation between the risk of internet addiction and problem behaviors. Also, the responses were based on self-report, resulting in the possibility of response bias. As a clear diagnostic criteria for internet addiction has not been established yet, the validity of KS scale needs to be verified.

One of the key strengths of our study was its large nationwide representative sample of Korean middle and high school students. Most of the previous research on internet addiction performed in Korea had a problem with opportunistic sampling. ${ }^{16,28,29)}$ It was also meaningful that gender-stratified analysis was performed in this study.

In conclusion, it appears reasonable to consider concurrent problem behaviors, especially smoking, drinking, drug abuse, and sexual intercourse, when dealing with adolescents with a high risk of internet addiction.

\section{CONFLICT OF INTEREST}

No potential conflict of interest relevant to this article was reported.

\section{REFERENCES}

1. Korea Internet Security Agency. 2011 Survey on the internet usage. Seoul: Korea Internet Security Agency; 2011.

2. Borzekowski DL. Adolescents' use of the Internet: a controversial, coming-of-age resource. Adolesc Med Clin 2006; 17:205-16.

3. Choi K, Son H, Park M, Han J, Kim K, Lee B, et al. Internet overuse and excessive daytime sleepiness in adolescents. Psychiatry Clin Neurosci 2009;63:455-62.

4. Ko CH, Yen JY, Yen CF, Chen CS, Chen CC. The association between Internet addiction and psychiatric disorder: a review of the literature. Eur Psychiatry 2012;27:1-8.

5. Yen JY, Ko CH, Yen CF, Wu HY, Yang MJ. The comorbid psychiatric symptoms of Internet addiction: attention deficit and hyperactivity disorder (ADHD), depression, social 
phobia, and hostility. J Adolesc Health 2007;41:93-8.

6. Mitchell P. Internet addiction: genuine diagnosis or not? Lancet 2000;355:632.

7. Young KS. Internet addiction: the emergence of a new clinical disorder. Cyberpsychol Behav 1998;1:237-44.

8. Shapira NA, Lessig MC, Goldsmith TD, Szabo ST, Lazoritz M, Gold MS, et al. Problematic internet use: proposed classification and diagnostic criteria. Depress Anxiety 2003; 17:207-16.

9. Shaw M, Black DW. Internet addiction: definition, assessment, epidemiology and clinical management. CNS Drugs 2008;22:353-65.

10. American Psychiatric Association. APA announces draft diagnostic criteria for DSM-5: new proposed changes posted for leading manual of mental disorders [Internet]. Arlington: American Psychiatric Association; c2010 [cited 2012 Nov 15]. Available from: http://www.dsm5.org/Newsroom/ Documents /Diag\%20\%20Criteria\%20General\%20 FINAL\%202.05.pdf.

11. Christakis DA. Internet addiction: a 21st century epidemic? BMC Med 2010;8:61.

12. Chakraborty K, Basu D, Vijaya Kumar KG. Internet addiction: consensus, controversies, and the way ahead. East Asian Arch Psychiatry 2010;20:123-32.

13. Block JJ. Issues for DSM-V: internet addiction. Am J Psychiatry 2008;165:306-7.

14. Ko CH, Yen JY, Yen CF, Chen CS, Weng CC, Chen CC. The association between Internet addiction and problematic alcohol use in adolescents: the problem behavior model. Cyberpsychol Behav 2008;11:571-6.

15. Yen JY, Ko CH, Yen CF, Chen CS, Chen CC. The association between harmful alcohol use and Internet addiction among college students: comparison of personality. Psychiatry Clin Neurosci 2009;63:218-24.

16. June KJ, Sohn SY, So AY, Yi GM, Park SH. A study of factors that influence Internet addiction, smoking, and drinking in high school students. Taehan Kanho Hakhoe Chi 2007;37: 872-82.

17. Korea Centers for Disease Control and Prevention. Korea youth risk behavior web-based survey [Internet]. Cheongwon: Korea Centers for Disease Control and Prevention; c2010 [cited 2012 Nov 15]. Available from: http://yhs.cdc.go.kr.

18. Korea Centers for Disease Control and Prevention. Korea youth risk behavior web-based survey: survey summaries. Cheongwon: Korea Centers for Disease Control and Prevention; 2010.

19. Kim BG, Kim DI, Kim DM, Ko YS, Eom NR, Lee EA, et al. The follow up study of internet addiction proneness scale. Seoul: National Information Society Agency; 2008.

20. Davis RA. A cognitive-behavioral model of pathological internet use. Comput Human Behav 2001;17:187-95.

21. Kim DI, Chung YJ, Lee EA, Kim DM, Cho YM. Development of internet addiction proneness scale-short form (KS scale). Korean J Couns 2008;9:1703-22.

22. Jessor R. Problem-behavior theory, psychosocial development, and adolescent problem drinking. Br J Addict 1987;82:33142.

23. Jessor R. Risk behavior in adolescence: a psychosocial framework for understanding and action. J Adolesc Health 1991;12:597-605.

24. Basen-Engquist K, Edmundson EW, Parcel GS. Structure of health risk behavior among high school students. J Consult Clin Psychol 1996;64:764-75.

25. Ko CH, Yen JY, Chen CC, Chen SH, Wu K, Yen CF. Tridimensional personality of adolescents with internet addiction and substance use experience. Can J Psychiatry 2006;51:887-94.

26. Fisoun V, Floros G, Siomos K, Geroukalis D, Navridis K. Internet addiction as an important predictor in early detection of adolescent drug use experience-implications for research and practice. J Addict Med 2012;6:77-84.

27. Grant JE, Potenza MN, Weinstein A, Gorelick DA. Introduction to behavioral addictions. Am J Drug Alcohol Abuse 2010;36:233-41.

28. Kim YS, Ahn DH, Kim YY. The relationship between problematic internet use and health risk behavior in community high school students. J Korean Acad Child Adolesc Psychiatry 2007;18:130-7.

29. Lee MS, Kim KY, Ko KJ, Lee HJ, Nam W, Kim EY, et al. A study on the related factors with internet addiction of the 11 th grade students in an urban area. Korean J Prev Med 2003;36:390-8. 